\title{
OBJECTIFICATION OF PUBLIC BUS STOP'S PAVEMENT SURFACE MORPHOLOGY
}

\author{
Martin DECKÝ1,*, Matúš KOVÁČ ${ }^{1}$, Juraj MUŽíK², Lenka MIČECHOVÁ ${ }^{3}$, Lukáš \\ DUURIS $\breve{S}^{3}$
}

${ }^{1}$ Department of Highway Engineering, Faculty of Civil Engineering, University of Žilina, Univerzitná 8215/1, 01026 Žilina, Slovakia.

${ }^{2}$ Department of Geotechnics, Faculty of Civil Engineering, University of Žilina, Univerzitná 8215/1, 01026 Žilina, Slovakia.

${ }^{3}$ Research Centre, University of Žilina, Univerzitná 8215/1, 01026 Žilina, Slovakia.

corresponding author: martin.decky@fstav.uniza.sk.

\begin{abstract}
The article deals with the road pavement surface morphology objectification in term of the surface unevenness degradation during the life cycle of bus stop pavements. The article presents the results of long-term rut depth measurements performed during 25 years on selected bus stops which were intended to determine correlation dependences of pavement rut depth on a number of design axles. The article also presents different methods for rut depth measurements including the straightedge test, Profilograph GE, TRIMBLE CX, and dynamic Road Scanner.
\end{abstract}

\section{Keywords:}

Bus stop;

Pavement;

Surface morphology;

3D scanning;

TRIMBLE CX.

\section{Introduction}

In the presented article the results of long-term research activities of authors in the field of pavement surface quality objectification with a priority focus on the pavement surface evenness $[1,2,3]$ represents an integral part of the pavement surface morphology. The morphology of the surface of the pavements is the immediate arrangement of all the elements of the road surface. This is a summary of all deviations of surface points from the ideal (projected) surface, which are in the vertical represented as a random combination of waves with different wavelengths and amplitudes. These variations determine the immediate value of the variable parameters. One of the major dynamic [4] capacity [5,6] and technological problems of urban communications is the pavement construction of the public transport stops which it is appropriate to build the same structure as the straight through road lanes.
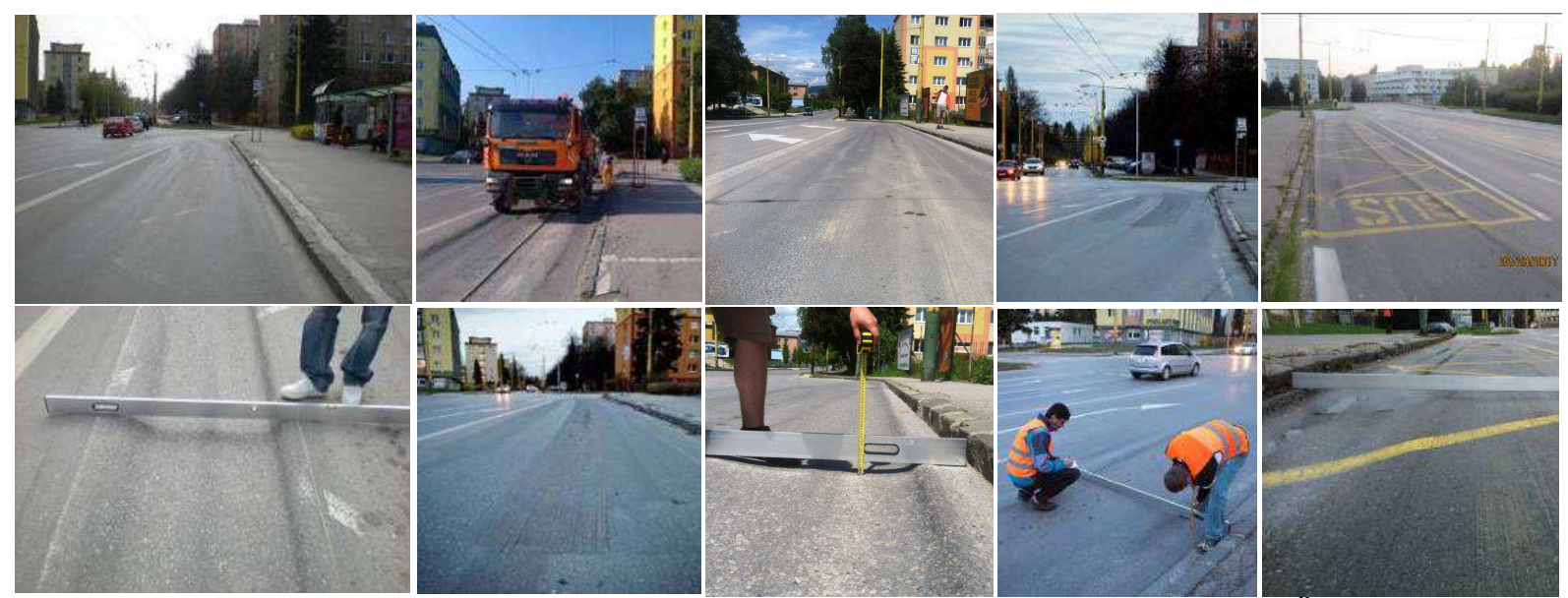

Fig. 1: Transverse unevenness of a road surface of the public bus stop "Mostná" in Zilina on 21 April 2010, 12 August 2013, 21 June 2016, and 29 August 2017 (left to right). 
The pavements of local communications are the most common constructed to asphalt and, however, when you use them on bus lanes the longitudinal ruts are created after some time, which undermine the operational characteristics of the road (water in ruts, etc.), but also its aesthetic appearance (Fig. 1 and Fig. 2).

\section{Permanent deformations of bus stops}

Permanent deformation in asphalt roads with heavy truck and bus services are related to the thermoplastic properties of the asphalt, and in our conditions, they cannot be fully avoided. There is the frequent presence of the permanent deformations of asphalt and paved roadways of public transport bus stop, and also the ruts are more common and deeper (Fig. 1 and Fig. 2).
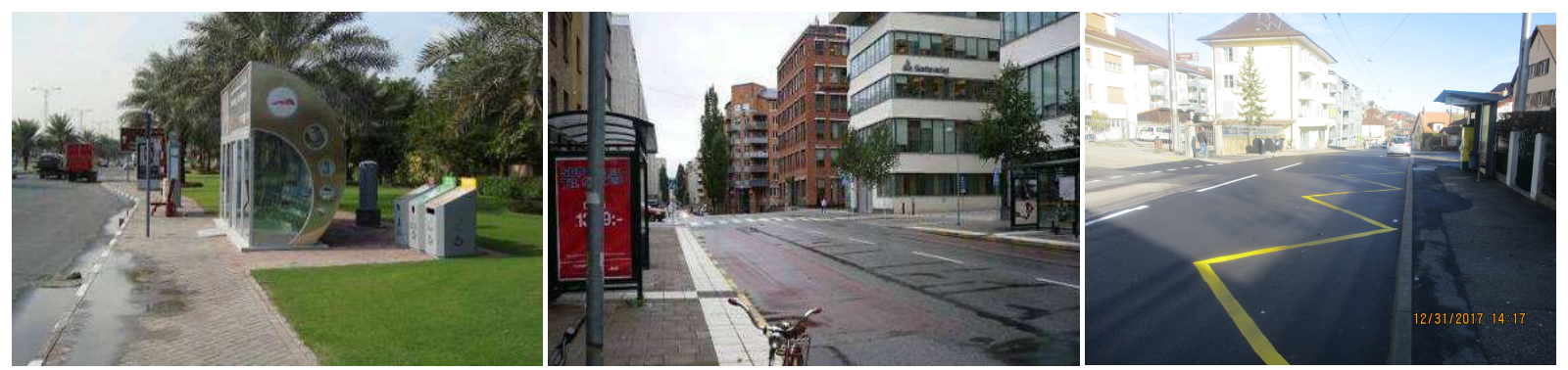

Fig. 2: Permanent deformation of Dubai, Stockholm, Neuchatel asphalt pavements of bus stops.

The cause of the increased formation of permanent deformations on the surfaces of public transport bus stops roads is the combined effect of vertical and horizontal forces acting on the roadway with intensive effect at temperatures above $20^{\circ} \mathrm{C}$. The effect of vertical forces is shown as the formation of vertical and radial stresses in the road structure. The stress curve inside the road structure is schematically shown in Fig. 3.

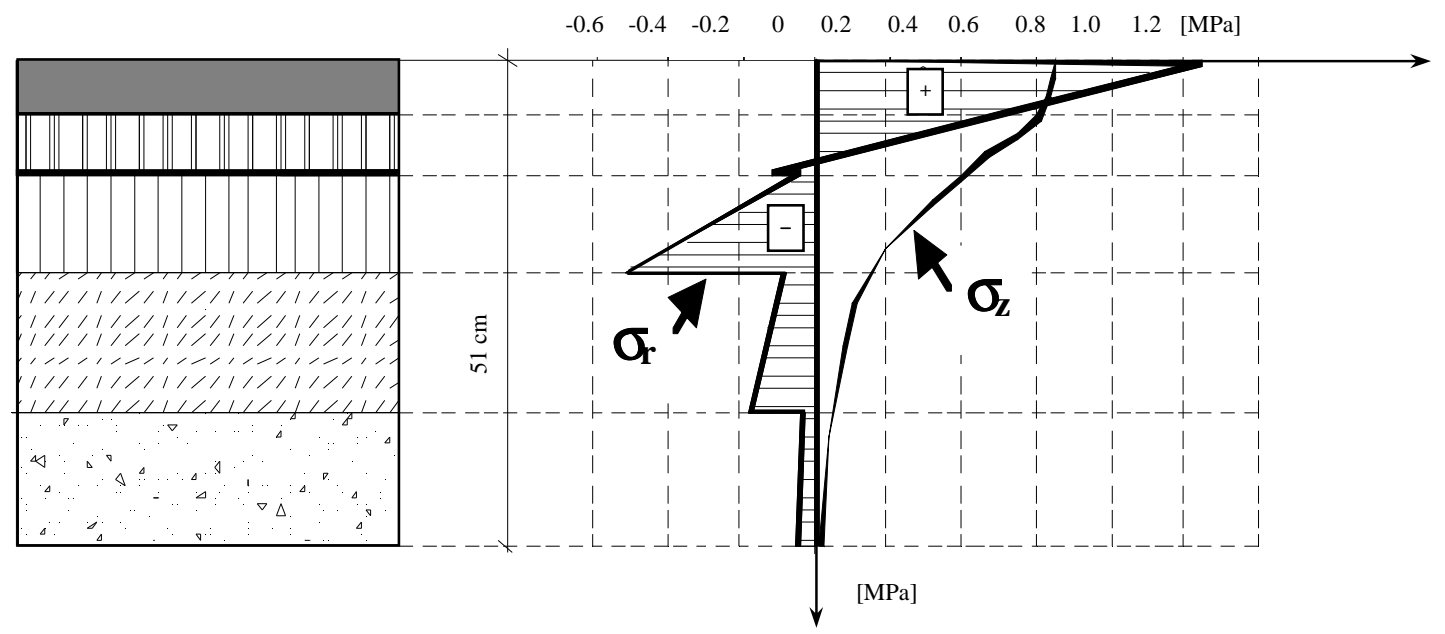

Fig. 3: The graphical view of vertical and radial stresses in the structure of asphalt pavement.

As shown by measurements of the permanent deformations, carried out for more than 30 years in the workplace of authors, where the road bus stops and highways were monitored over the long term, the permanent deformation under the same number of axle run is more than double times the larger. For a comparison of the results, the measurements from the '80s and '90s of the 20th century are shown in Fig. 4. 


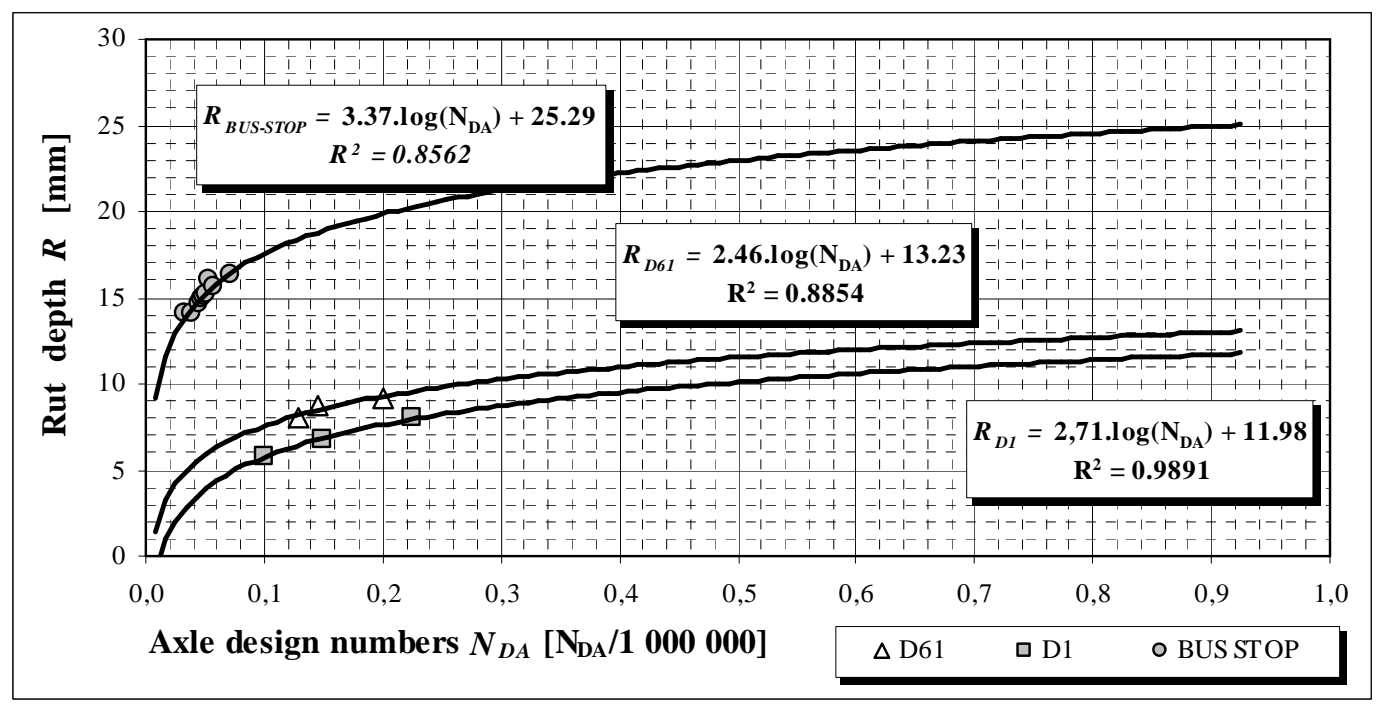

Fig. 4: Comparison of the permanent deformation of the road surface of public bus stops in Žilina and highway roads D1 and D61 from the ' 80 s and '90s of the 20th century.

\section{Evaluation of transverse unevenness according to technical regulation TP 056}

In Slovak standard STN EN 13036-7 [7] unevenness is defined as the maximum difference between the surface and the edge of measuring staff in a segment between two points contact with the road surface, while the plate is laid perpendicular to the surface.

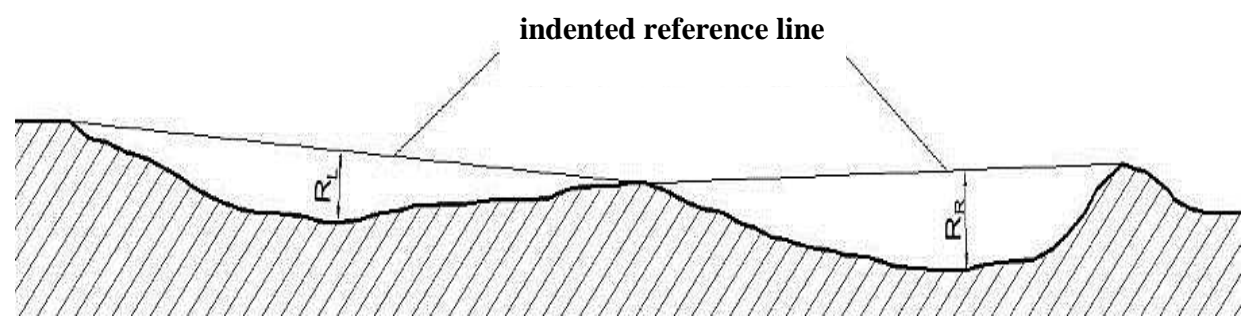

Fig. 5: Left and right rut depth of pavement surface according to technical regulation TP 056.

This standard describes the instrument and method for the measurement of the various unevenness that reflects the deficiencies in the quality of the new road surface layers, airports, and transport surfaces, as well as other surfaces in use. By TP 056 [8] is a rut depth $R[\mathrm{~mm}]$ defined as the perpendicular distance between the lowest point of wave and a line connecting the wave peaks (Fig. 5). A five-level classification system of road crosswise unevenness according to technical regulation TP $056[8]$ is given in Table 1.

Table 1: Evaluation of crosswise unevenness according to rut depth as defined in TP 056 [8].

\begin{tabular}{|c|c|c|c|}
\hline $\begin{array}{c}\text { Classification } \\
\text { level }\end{array}$ & Highways and motorways & $\begin{array}{c}\text { Roads of } \\
\text { I. and II. class }\end{array}$ & $\begin{array}{c}\text { 3rd class roads } \\
\text { and municipal roads }\end{array}$ \\
\hline 1 & $<5.00$ & $<5.00$ & $<10.00$ \\
\hline 2 & $5.01-10.00$ & $5.01-10.00$ & $10.01-15.00$ \\
\hline 3 & $10.01-15.00$ & $10.01-15.00$ & $15.01-20.00$ \\
\hline 4 & $15.01-20.0$ & $15.01-25.0$ & $20.01-30.00$ \\
\hline 5 & $>20.00$ & $>25.00$ & $>25.00$ \\
\hline
\end{tabular}

In the Slovak Republic, for the mass collection of data on the roadway longitudinal roughness, the instrument PROFILOGRAPH GE (Fig. 6 left) produced by the Danish company Greenwood Engineering Aps., is used. The instrument is owned by Road Databank of the Slovak Road Administration. Website of Road Databank of Slovak Road Administration describes that the Profilograph instrument consists of VW Multivan vehicle, measuring beam containing 16 laser sensors, 
3 accelerometers, 2 gyroscopes + control unit, length measuring instrument in the left rear wheel, the operational units (for the control of the system and the immediate presentation of data), software for calibration equipment and analysis of measured data, GPS.
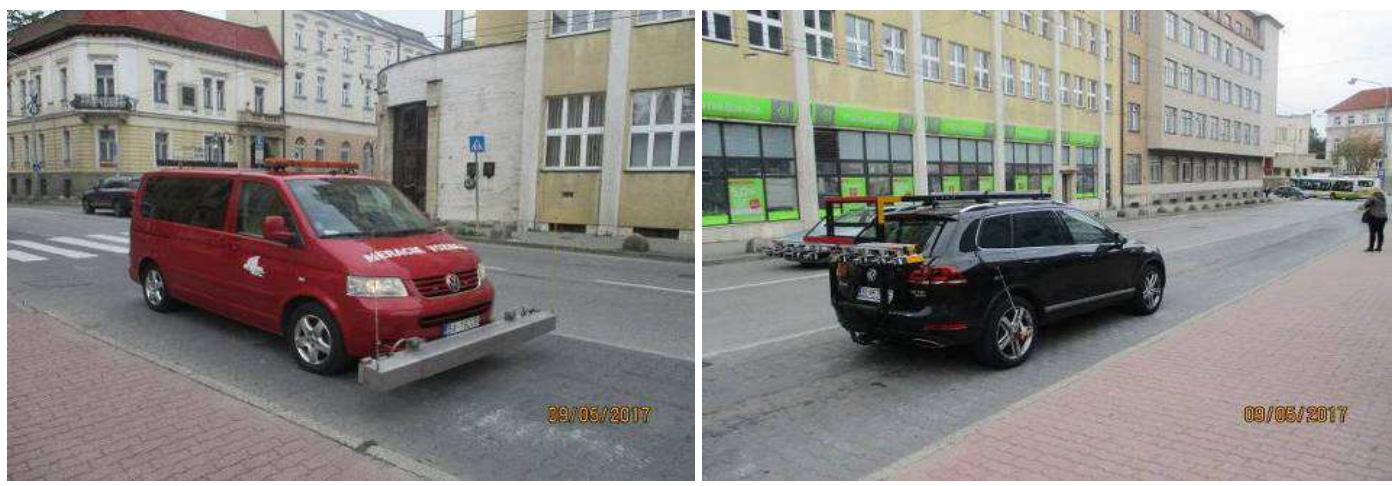

Fig. 6: View of measuring instrument Profilograph GE and Dynamic Road Scanner in measuring road surface morphology at the public bus stop "Hurbanova" in Žilina on 9 May 2017.

In the present, the Research Centre and the Faculty of Civil Engineering UNIZA in cooperation with the company KVANT are developing the brand-new device Dynamic Road Scanner (Fig. 6 right), which is an instrument for measuring the transverse and longitudinal unevenness. To scan the surface of the road, the instrument uses 8 devices Geocator 2375, scanning width in a single pass is $4 \mathrm{~m}$, scanning frequency is $2000 \mathrm{Hertz}(\mathrm{Hz})$ with 9600 measuring points to the width of $4 \mathrm{~m}$. Possibility to scan the road is up to the speed of $110 \mathrm{~km} / \mathrm{h}$.

\section{Objectification of the transverse roadway unevenness by the method of 3D scanning}

The main element of a laser measurement system is a laser scanner, the detector working on the principle of laser range finder that uses received information for further processing. Laser scanners types differ by the use and currently we distinguish terrestrial, stationary, or mobile scanners [9]. Stationary scanners are usually mounted on a tripod (Fig. 7) or on a special base for scanning objects; the mobile scanners can be installed on the vehicle (Fig. 6), an airplane, or a helicopter.
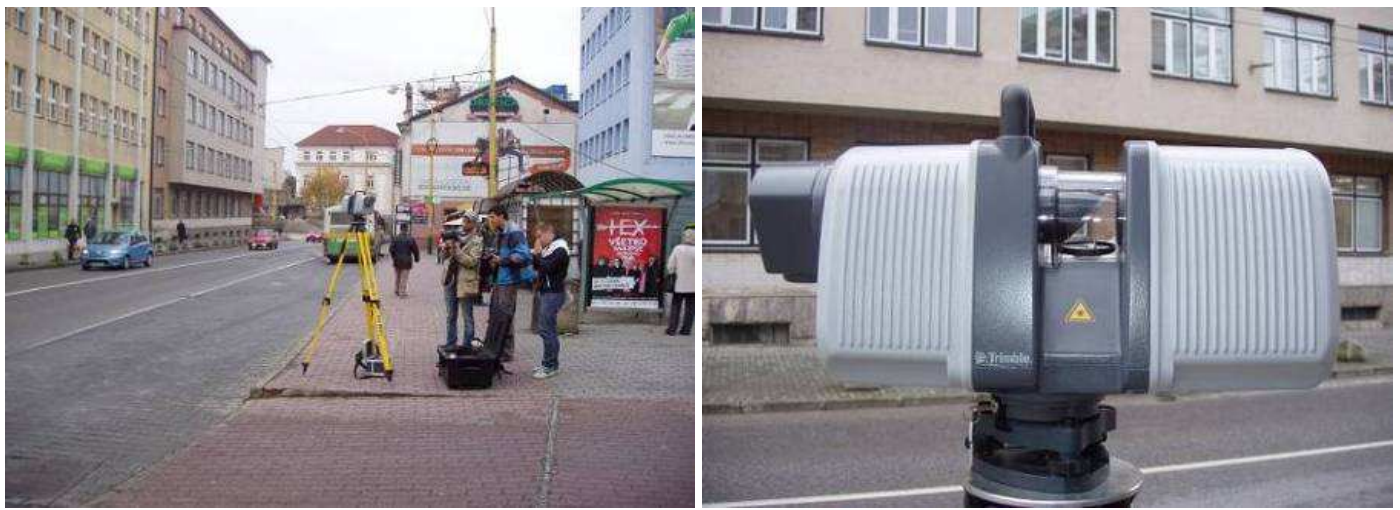

Fig. 7: The Trimble CX instrument during the road surface measurement of the public bus stop "Hurbanova" in Žilina on 22 October 2015.

The current systems are capable of scanning the desired object using a 3D scanner, and use the program to create a cloud of points corresponding to the scanned object. Today's scanners have very sensitive mirror cameras built-in that record the surface of the scanned object and preserve the nature of the textures. The output of such a system is a very accurate 3D copy of the scanned object in reduced scale. For the application of laser scanning of the road pavement unevenness, the Faculty of Civil Engineering UNIZA uses the terrestrial laser scanner Trimble CX (Fig. 6) that uses a combined method of measurement, pulse (time-of-flight) and phase (phase shift). The reach of the device is up to $80 \mathrm{~m}$ under $90 \%$ reflectivity conditions and up to $50 \mathrm{~m}$ under $18 \%$ reflectivity. Scanning speed is 54.000 points per second. Standard deviation is $1 \mathrm{~mm}$ per $30 \mathrm{~m} ; 1.8 \mathrm{~mm}$ per $80 \mathrm{~m}$, for the horizontal 
angle the standard deviation is 15 " and for the vertical angle 25". The accuracy of modelled surface is $\pm 3 \mathrm{~mm}$, size of the laser beam mark is $8 \mathrm{~mm}$ at 25 meters; $13 \mathrm{~mm}$ to $50 \mathrm{~m}$, minimal angle step is $0.002^{\circ}$.

The first measurement of a road surface unevenness of the public bus stop "Hurbanova" in Žilina using instrument Trimble CX was carried out by J. Mužík and A. Villim in the year 2013 and point cloud data processed using Trimble Realworks 6.0 (Fig. 8). The outputs of the Trimble Realworks 6.0 programme can be imported into AutoCAD in.dwg or.ptc file format.
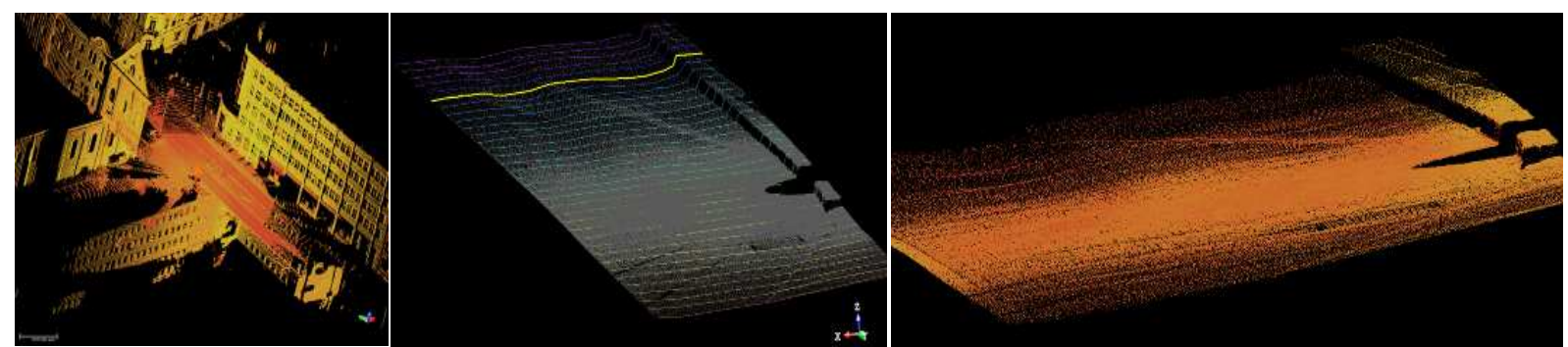

Fig. 8: Perspective view on the raw point cloud with the capture of the surrounding buildings (left), a point cloud for the processing of cross profiles (centre), and the point cloud with generated transverse profiles of the road surface (right).

The second measurement of the road surface was carried out on 22 October 2015 using two standpoints during full traffic without direct contact with the road surface (the time required to perform a detailed scan on one standpoint was $3 \mathrm{~min}$.).
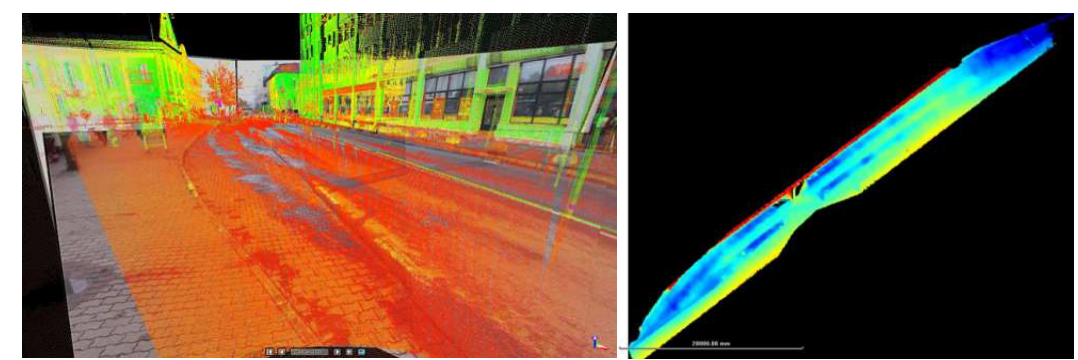

Fig. 9: Perspective view from standpoint No. 2, together with the underlying images (left), height map of the surface obtained from the point cloud (right).

On a height map of the surface, the distortions of the surface in the form of a rut, are very clearly visible. The height map is the basis for more detailed quantification of deformations. Subsequently, the profiles, showing the shape of the road surface, were generated, creating the possibility for the general expression of the status of the road and assessment of general condition, along with the determination of the limits of deformations. 

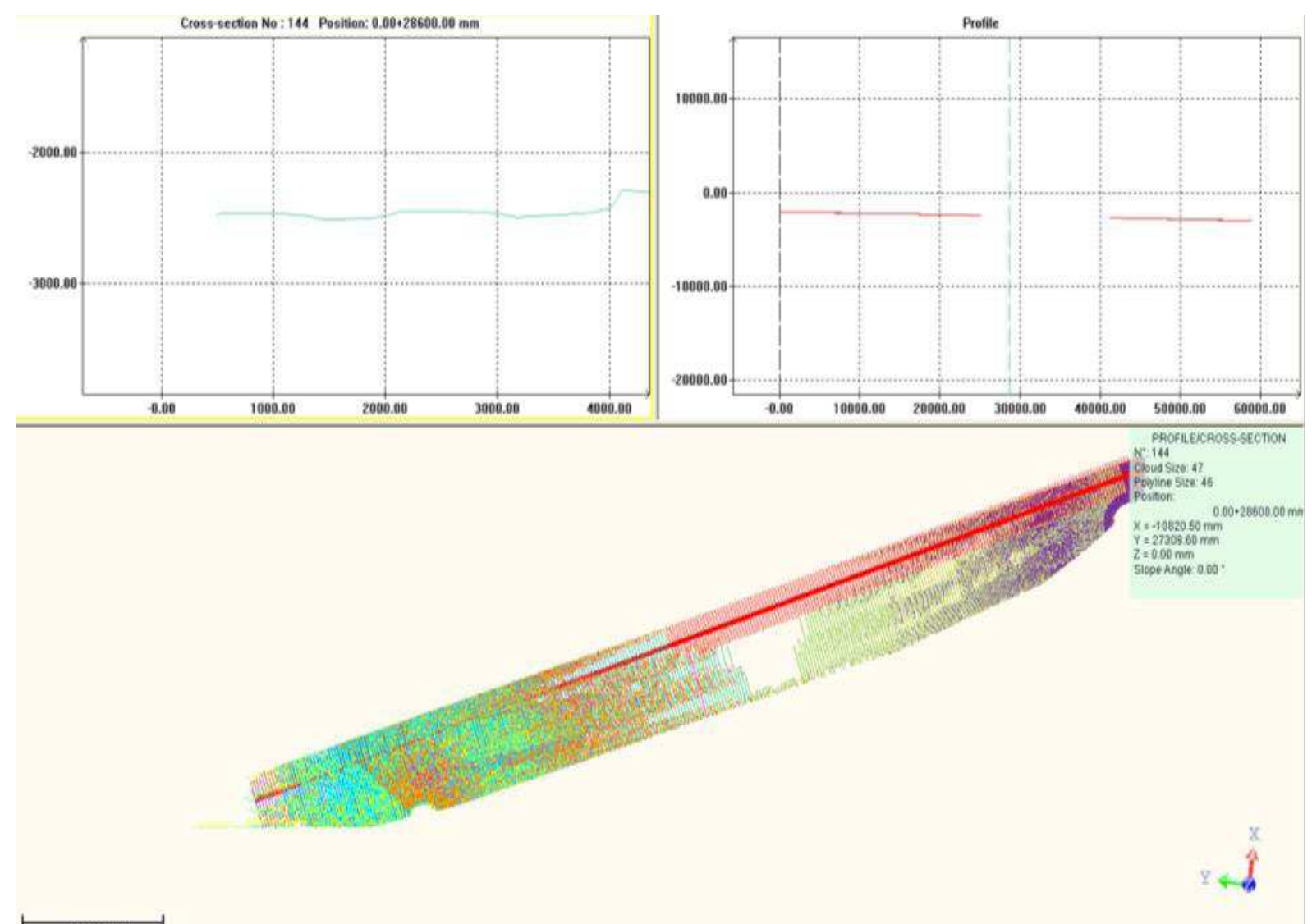

Fig. 10: Profile 83 (right upper section) in the first part of the road and the profile 144 (left upper section) in the second part of the road.

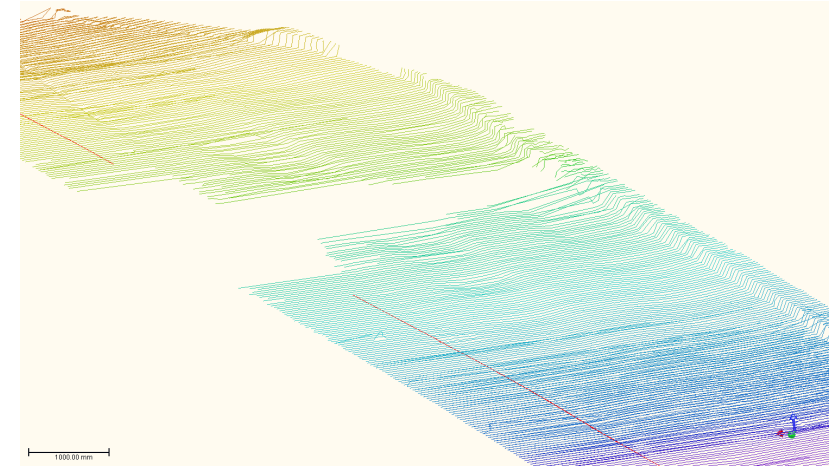

Fig. 11: Generated profiles and visible unevenness on the surface of the bus stop "Hurbanova" in Žilina on 22 October 2015.

Using the generated profiles a comparison with the traditional methods of measuring of unevenness can be carried out. While it was determined that the maximum value of right rut depth $R_{R \max }=76 \mathrm{~mm}$ and left value $R_{L \max }=36 \mathrm{~mm}$, which is quite an exact match with the data obtained by measurement using a measuring staff (Fig. 11).

\section{Correlation dependences of pavement rut depth on axle numbers}

The behavior of the pavement during the operation was constitutionally monitored by measuring the transverse unevenness of the bus stop "Hurbanova" in Žilina (Fig. 12) and measurements were made at least once a year using UNIZA's profilograph [3]. 


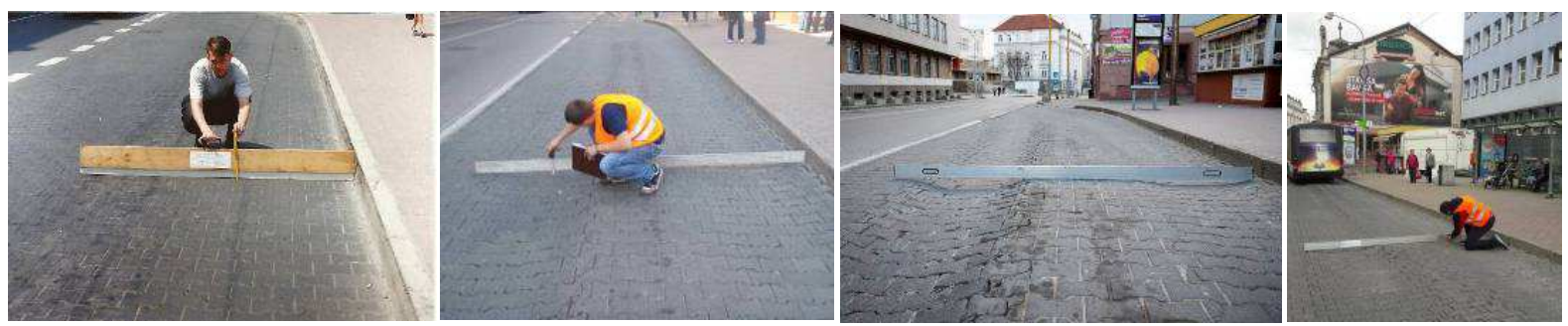

Fig. 12: Views of measurement process for determination of rut depth after the run of 160000 design axles (DA) - on 27 August 1994, in the year 2012 after $N_{A D}=3.4 \cdot 10^{6}, 2012,2015$ after $N_{D A}=4 \cdot 10^{6}$ (Centre) and after $N_{D A}=4.5 \cdot 10^{6}$.

Possible monitored characteristics of pavement transverse unevenness in our case was a depth of ruts. The characteristic graph of surface unevenness after a run of 400000 axles is shown in Fig. 13 and results of measurements in the years 1993 - 1998 are in graphical interpretation presented in Fig. 13.
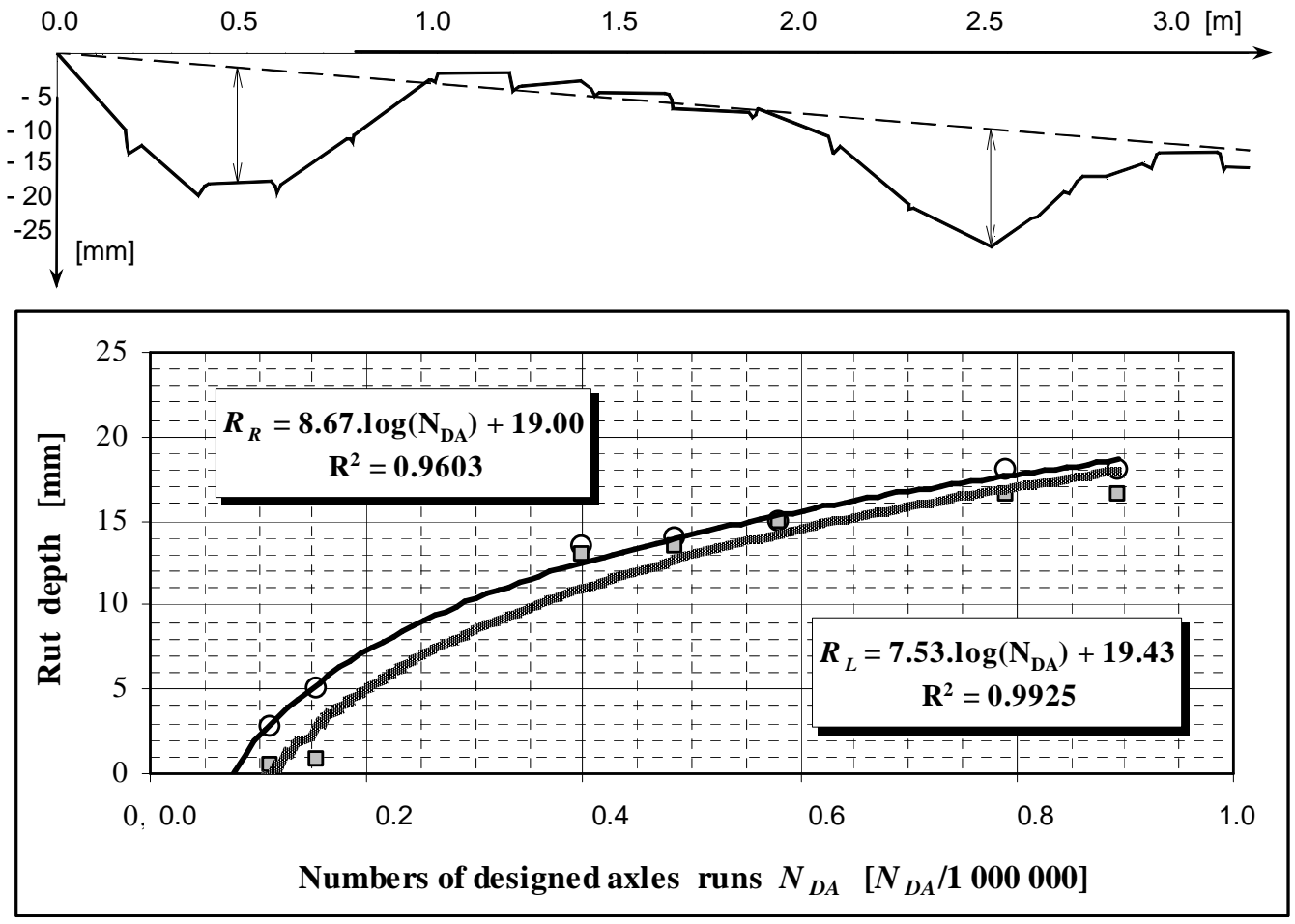

Fig. 13: View of evaluated transverse unevenness of the surface of the bus stop "Hurbanova" and correlation dependence of rut depth on axle numbers.

On the basis of the long-term relevant results obtained was created by degradation model for maximum rut depth, where it was measured throughout the reporting period (Fig. 14). 


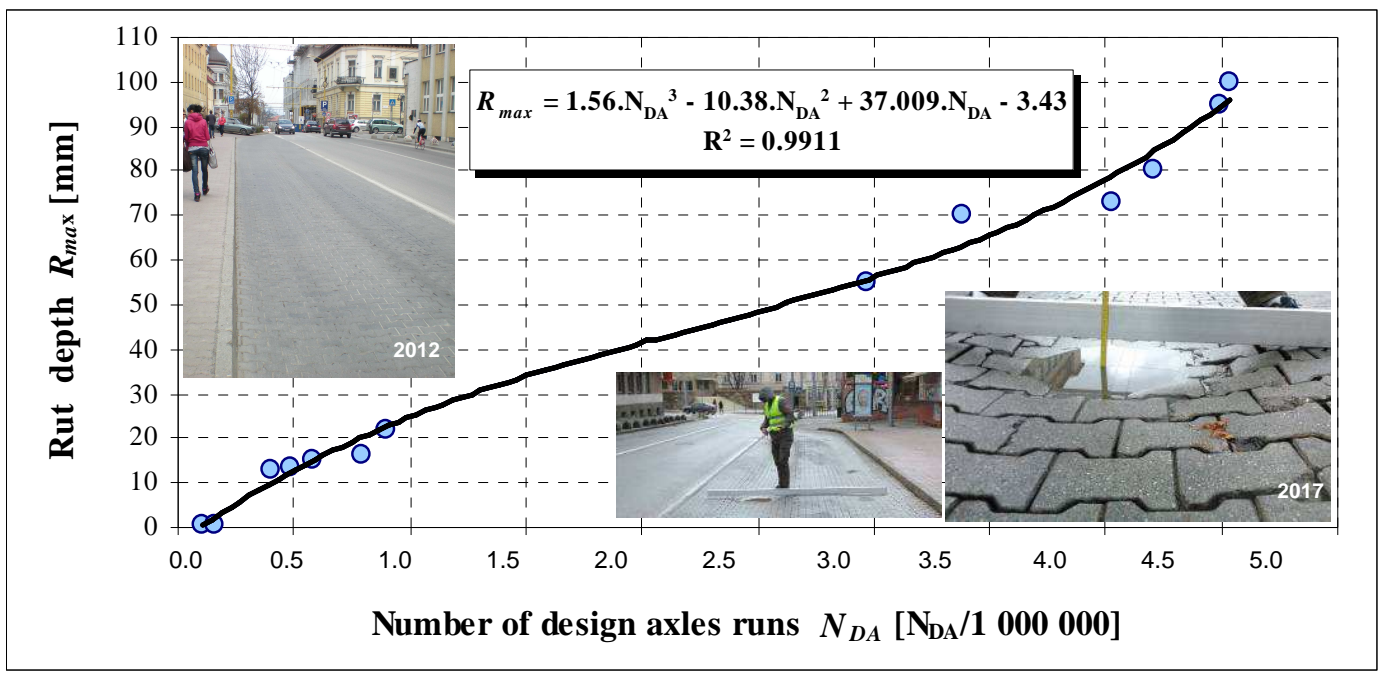

Fig. 14: Development of the rut depth, depending on the number of crossings of design axles for the public bus stops "Hurbanova" in Žilina.

As is apparent from the observations made, the problem of the quality of construction of bus and tram stops is still high. In many towns in Slovakia, it is possible to see that the normal asphalt pavement constructions are often in very poor condition severely deformed and therefore are not suitable for public bus stops.

\section{Conclusion}

In the article were presented the results of long-term rut depth measurements performed during 25 years on selected bus stops which were intended to determine correlation dependences of pavement rut depth on a number of design axles. However, the found dependencies of rut depth on number of design axles seem to be logarithmic at first (up to 1 million of design axles runs), it was shown that after 3 millions of design axle runs the dependencies confirmed the theoretical 3rd degree polynomial correlation function, which is typical for pavements with asphalt layers.

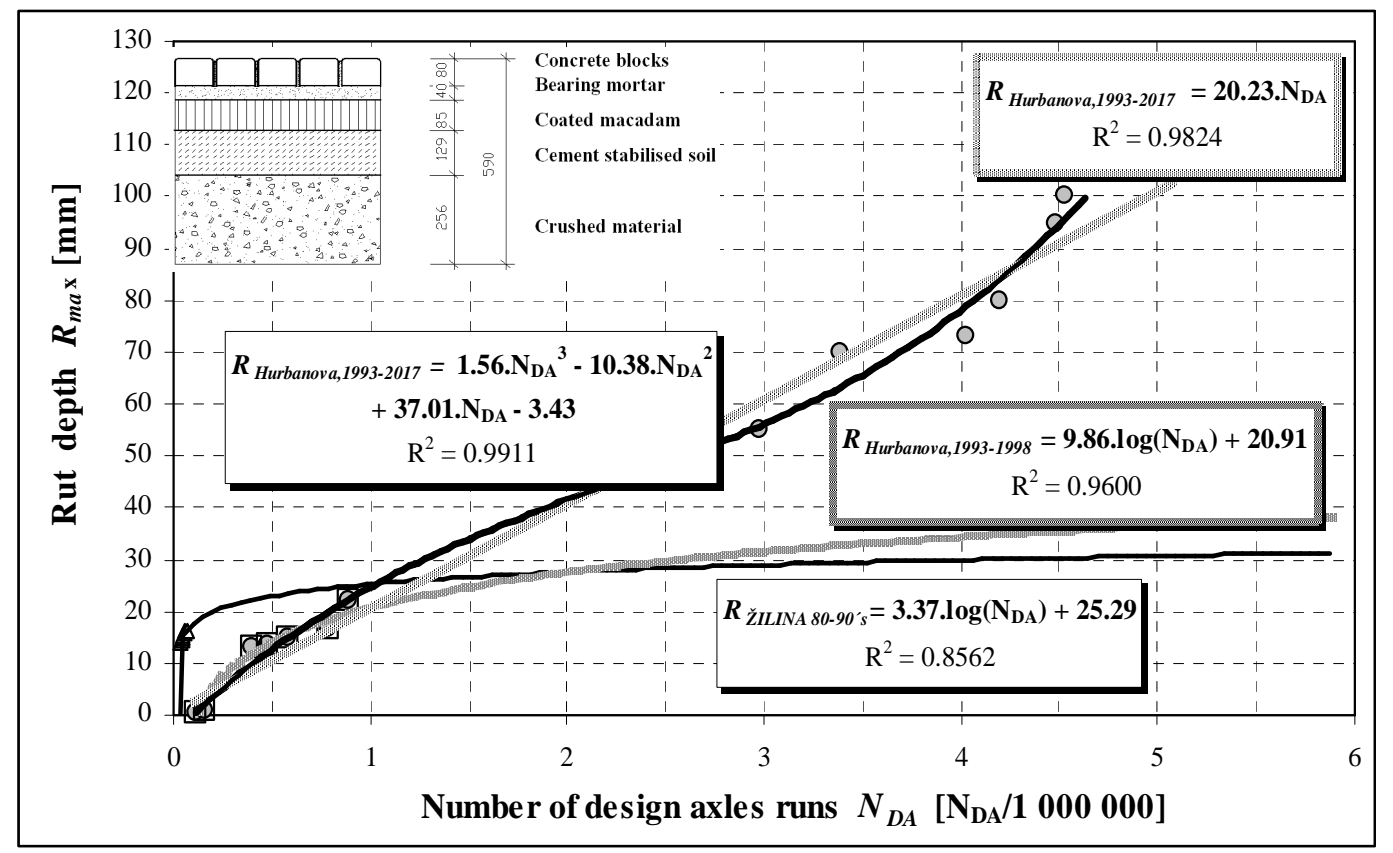

Fig. 15: Comparison of correlation dependences of the pavement bus stop rut depth on the design axle number obtained after the $N_{D A}=0.1 \cdot 10^{6}, N_{D A}=0.9 \cdot 10^{6}$, and $N_{D A}=4.5 \cdot 10^{6}$. 
Multi-annual experience suggests that the appropriate type of construction the bus stop can be a design with a paved cover. As it was shown by realized measurement of these structures also paved construction leads to the formation of permanent deformations but compared to pavements with asphalt wearing course the increment of permanent deformation is slower. Similarly, it can be positively assessed the overall status of the pavement after 5 years of operation with almost a million times runs of design axles, pavement structure doesn't show any significant deficiencies.

In the present, the Research Centre and the Faculty of Civil Engineering UNIZA in cooperation with the company KVANT are developing the brand-new device Dynamic Road Scanner for measuring the transverse and longitudinal unevenness. The example of the output of the device is shown in Fig. 16.
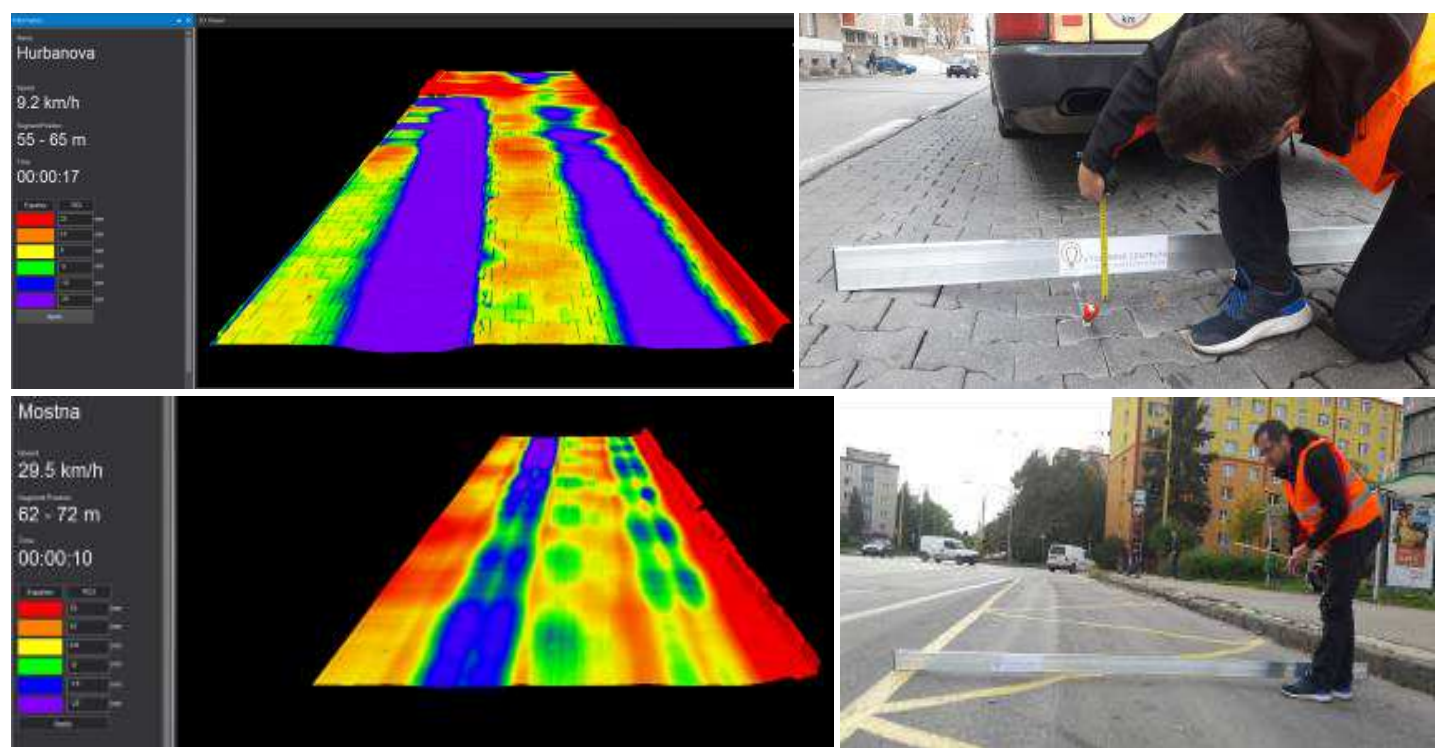

Fig. 16: Results of Dynamic Road Scanner measurements of the bus stops "Hurbanova" and "Mostná" in Žilina on 17 October 2017 and standardized measurements according to STN EN 13036-7.

\section{Acknowledgements}

The paper is a result of the research supported by the research project VEGA 1/0537/17 "The influence of pavement surface morphology on pavement serviceability and emissions production" and the European project ITMS 313011D011 "Research Centre of the University of Žilina - the second phase".

This contribution is the result of the project implementation: "Supporting research and development center of excellence for civil engineering" (ITMS: 26220120031) supported by the Research \& Development Operational Programme funded by the ERDF.

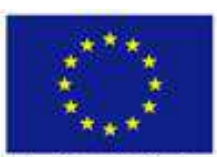

Európska únia

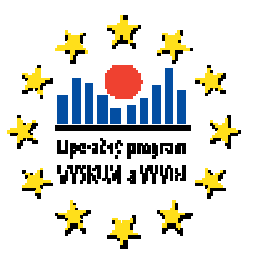

\section{References}

[1] ČELKO, J. - DECKÝ, M. - KOVÁČ, M.: An analysis of vehicle - road surface interaction for classification of IRI in the frame of Slovak PMS. Maintenance and reliability, Polish Maintenance society, Vol. 1, Iss. 41, 2009, pp. 15 - 21. 
[2] DECKÝ, M. - KOVÁČ, M. - KOTEK, P.: The comparison of measured and simulated dynamic responses of vehicles indicated by road pavement unevenness. Civil and Environmental Engineering, Vol. 11, Iss. 1, 2015, pp. 10 - 20.

[3] KOVAC, M. - DECKY, M. - LEITNER, B.: The objectification of road unevenness evaluation by the use of vehicle-pavement interaction simulation. Proceedings of the $20^{\text {th }}$ International Scientific Conference on Transport Means 2016, Juodkrante, Lithuania, 5 - 7 October 2016, pp. 450 - 453.

[4] RAPANOVA, N. - KORTIS, J.: Numerical simulation of pavement response to dynamic load. Transport and telecommunication journal, Vol. 14, Iss. 3, 2013, pp. 230 - 236.

[5] ZEMAN, K. - PETRU, J. - KRAMNY, J.: Roadways in public transport stops, their failures, and reconstruction option for the operation of modern high-capacity vehicles. Conference proceedings GeoConference on Nano, Bio, and Green - technologies for a sustainable future, 16 - 22 June 2013, Albena Bulgaria, pp. 705 - 711.

[6] MAHDALOVA, I. - PETRU J. - KRIVDA, V.: Assessment of the capacity of roads weaving segments. Transport and telecommunication journal, Vol. 18, Iss. 2, 2017, pp. 101 - 106.

[7] STN EN 13036-7 Road and airfield surface characteristics. Test methods. Part 7: Irregularity measurement of pavement courses the straightedge test, 2005.

[8] TP 056 Measurement and assessment of a road irregularity using the device PROFILOGRAPH GE, MDVRR SR, 2012.

[9] IZVOLTOVA, J. - PISCA, P. - KOTKA, V. - MANCOVIC, M: 3D laser scanning of railway line. Communications - Scientific Letters of the University of Žilina, Vol. 15, Iss. 4, 2013, pp. $80-84$. 